\title{
Wikificação como modelo de edição de conteúdos jornalísticos na web
}

Carlos Frederico de Brito d'Andrea*

Resumo: No artigo apresentamos a noção de "wikificação do jornalismo" como modelo de edição de textos na web. Este conceito relaciona as rotinas de produção na internet com a atual lógica de fluxo contínuo de informações e com a abertura à colaboração do público externo às redações. Inicialmente, problematizamos o crescente esvaziamento da edição jornalística na web e a fragmentação do conteúdo publicado por sites noticiosos. Em seguida, discutimos a tendência de participação do público na produção de notícias, a partir de três modelos de edição no ciberjornalismo propostos por Machado (2008). Por fim, levantamos possibilidades e desafios da "wikificação do jornalismo", entendido como um modelo de gestão de conteúdo baseado na colaboração e na atualização contínua de textos.

Palavras-chave: Webjornalismo; edição; colaboração.

\section{Wikification as a model of journalistic contents edition on the web}

Artigo recebido em: 15 de agosto de 2010 Aprovado em:

20 de setembro de 2010

* Professor assistente do departamento de Comunicação Social da Universidade Federal de Viçosa (UFV) e doutorando em Estudos Linguísticos (Linguagem e Tecnologia) pela Fale/UFMG.

carlosdand@gmail.com

\begin{abstract}
In the article we present the term "wikification of journalism" as a model of text editing on the web. This concept relates the production routines of news on the Internet with the current logic of continuous flow of information and collaboration with the opening to the public outside the newsroom. Initially, we discussed the growing issue of journalistic dissection and fragmentation of the web content published by news sites. Then we discuss the trend of public participation in news production, from editing in three models cyberjournalism proposed by Machado (2008). Finally, we raise opportunities and challenges of "wikification of journalism", understood as a model of content management based on collaboration and continuous updating of texts.
\end{abstract}

Keywords: Webjournalism; editing; colaboration. 


\section{Introdução}

1 fragmentação do conteúdo publicado e a edição colaborativa são, atualmente, duas características marcantes da produção textual na e para a internet. Na lógica da instantaneidade, é cada vez mais comum, especialmente em sites jornalísticos, a publicação contínua de notas e matérias sobre acontecimentos, especificamente os de grande repercussão. Uma consequência deste processo é a fragmentação do conteúdo jornalístico em diversas páginas publicadas à medida que novas informações sobre um acontecimento são apuradas ou recebidas pela equipe editorial. De forma complementar, a crescente participação do público leigo nas rotinas de produção jornalística tem obrigado as empresas e os profissionais da área a conceber novos modelos de edição de conteúdo que conciliem a abertura à produção descentralizada e a preservação do rigor que caracteriza o jornalismo.

Machado (2008) destaca três características que diferenciam os "novos e mais complexos modelos de edição” que emergem no atual contexto, marcado pela adoção de sistemas dinâmicos de gestão de conteúdo e pela descentralização da produção: as "funções atribuídas a jornalistas e leigos"; o "número de etapas existentes no processo" e a "capacidade de inserção dos membros da rede de circulação de notícias no trabalho contínuo de edição dos conteúdos publicados" (p.5-6).

Neste contexto, apresentamos a noção de “wikificação do jornalismo" como um modelo de edição de textos na web. Ao mesmo tempo em que aproxima as rotinas de produção à lógica de fluxo contínuo de tratamento e publicação de informações, a wikificação problematiza e considera a abertura à colaboração do público externo, procurando, em última instância, desenvolver processos mais complexos do que a esvaziada atividade de edição adotada por sites e portais noticiosos na atualidade.

\section{Envaziamento da edição, fragmentação dos textos}

A informatização das redações jornalísticas, iniciada ainda nos anos de 1980, e o acirramento da competição entre grupos de mídia e de outros setores (e uma consequente mudança nos modelos de gestão empresarial) são alguns dos fatores que trouxeram progressivos impactos sobre a rotina de produção de conteúdos jornalísticos nos últimos anos. Nesse contexto, identificamos estar em franca readequação um modelo de funcionamento das redações jornalísticas consolidado ao longo do século XX. Baseado em algumas etapas de produção e no esforço para formalização de cargos e/ou funções hierárquicas, esse modelo tem no repórter uma figura central, pois é ele quem articula o "amadurecimento" do texto na rede de produção de uma redação, além de assinar a versão publicada. No entanto, considerando que o texto jornalístico é o resultado de muitas reescritas e retextualizações, em momentos iniciais e finais da construção da notícia, diferentes profissionais, como os pauteiros, revisores, copidesques, checadores e, em especial, editores, trabalham (ou trabalhavam) na adequação e correção do texto antes de sua publicação. 
Dentre as diferentes intervenções às quais pode passar o material jornalístico, interessa-nos discutir especificamente a edição, aqui entendida como uma etapa em que se busca dar o acabamento adequado a um material jornalístico, seja hierarquizando o material, seja dando a ele o tratamento gráfico e verbal alinhado ao conceito editorial da publicação. Como sintetiza Pereira Júnior (2006, p.22), "editar significa valorizar a informação. Hierarquizar".

Para Marocco \& Berger (2006), a edição de uma publicação jornalística está inscrita em um quadro complexo de produção que conjuga o gesto individual, as estratégias empresariais e as pautas jornalísticas. De forma complementar, Pereira Júnior (2006) afirma que a submissão do texto a várias etapas de edição permite que o material seja moldado pelas diferentes forças às quais estão submetidas a atividade jornalística. Nas palavras do autor, "cada filtro de edição dá couraça objetiva a decisões de motivação, em última instância, subjetiva, organizacional ou restrita à comunidade profissional (...)” (p.24).

A partir da década de 1990 , a adequação da produção jornalística às especificidades tecnológicas e às condições organizacionais de sites e portais tem intensificado a ruptura com o modelo citado anteriormente. Identificase hoje, de forma cada vez mais clara, uma simplificação das operações e etapas de tratamento do texto, assim como uma redução no número de profissionais envolvidos nessa rotina. Sobre o impacto da adoção dos computadores, Soster (2006, p. 36) registra que "papéis até então usuais nas hierarquias das redações, caso do revisor e do subeditor, foram gradativamente extintos, ou fragilizados em sua importância, aumentando a responsabilidade dos repórteres sobre o resultado final das matérias”. De forma cada vez mais intensa, repórteres ou redatores dos sites noticiosos têm grande autonomia para realizar, sozinhos, "todo" o ciclo que envolve o jornalismo, "sem nenhum filtro aparente ou editores que desempenhem o papel de revisão e edição" (MARTINEZ, 2007, p. 16).

Uma das causas desta mudança é o enxugamento das redações, principalmente de jornais impressos. Em levantamento recente, Stepp (2009) identificou que os cortes nas redações de veículos estadunidenses impactaram mais a função de editor do que os repórteres. Repercutindo esta informação, Duarte (2009) complementa lembrando que "repórteres estão assumindo funções cada vez mais relevantes no fechamento" das publicações diárias. Segundo Soster (2006, p. 36), são hoje "pouco perceptíveis as fronteiras entre quem escreve e quem edita, diluindo a figura do editor". Em função do ritmo de produção, do enxugamento das redações e das mudanças nas hierarquias, assim como das novas possibilidades e condicionamentos tecnológicos, torna-se cada mais comum, por exemplo, a "auto-publicação" de matérias, especialmente na produção voltada para a internet.

Essa nova configuração das rotinas de produção no webjornalísmo foi identificada em estudos como o realizado por Pereira (2004) na redação do CorreioWeb, em Brasília; por Jorge (2007), que pesquisou o portal UOL, em São Paulo; e Barbosa (2003), que analisou os portais regionais UAI (ligado ao grupo Diários Associados, em Belo Horizonte) e IBAHIA (do Grupo Rede 
Bahia, em Salvador). Em geral, os autores identificaram um acúmulo de funções por parte dos jornalistas e a falta de interlocução com outros profissionais, inclusive editores.

Como forma de compensar a crescente "horizontalização" das relações entre repórteres e editores, novas formas de edição estão sendo adotadas nas redações. Stepp (2009), por exemplo, identificou a edição por um colega próximo, a edição posterior à publicação de uma notícia ou o envio do material para um editor para conferência e publicação através de um sistema que permita pré-visualização como práticas comuns nas redações estadunidenses.

Associada à tendência de "auto-publicação", a adaptação da produção jornalística para a internet foi duramente submetida a algumas características do meio, como a possibilidade de publicação instantânea de uma informação e o rompimento da lógica de ciclos periódicos em prol de um "deadline contínuo". Como afirma Martinez (2007, p.15), "em menos de cinco anos de funcionamento da internet, aquela noção de ordem e de rotina produtiva ditada pelos meios industriais (...) foi subvertida pelo ritmo frenético do noticiário no ciberespaço". Este fenômeno, vale registrar, não é uma exclusividade da internet, podendo ser observado, guardadas as especifidades, nos meios eletrônicos, como a televisão e o rádio ${ }^{1}$.

$\mathrm{Na}$ internet, uma consequência desse processo é a fragmentação do conteúdo jornalístico em diversas páginas da web, que passam a ser publicadas à medida que novas informações sobre um acontecimento são apuradas ou recebidas pela equipe editorial. Atualmente, como afirma Silva Júnior (2008, p. 10), "o limite da velocidade operacional dos jornais em sincronizar e reduzir o tempo dos eventos ao tempo da publicização dos informes é condicionado pela velocidade das agências no repasse dos serviços" ${ }^{\prime 2}$. Na lógica da instantaneidade e do fluxo contínuo de publicações, textos mais bem-acabados muitas vezes dão lugar a sequências de notas jornalísticas que não configuram uma "suíte", inclusive por serem contraditórias entre si e sem uma articulação contextual suficiente para a compreensão dos fatos pelo público.

Langeveld (2009), ao refletir sobre a atual dinâmica de produção e circulação de informações de interesse jornalístico, propõe a adoção do termo "cascata de conteúdos" ("content cascade", em inglês) para designar o fluxo ininterrupto de informações com o qual uma redação deve estar preparada para lidar, seja produzindo, agregando e editando. Para o autor, torna-se cada vez mais

\footnotetext{
'Betti e Meditsch (2008), ao discutir a implementação das rádios all news no Brasil, identificam a transição de uma "grade generalista", baseada em programas sequenciados e com horários marcados, para um "fluxo contínuo de informação", em que uma informação é interligada a outra de forma aparentemente ininterrupta.

2 Para Martinez (2007), esse problema deve-se a um rompimento da separação histórica entre as rotinas e papel das agências de notícias e das redações jornalísticas. As primeiras, que sempre tiveram na rapidez (a partir dos meios técnicos disponíveis) e na precisão suas características diferenciais, serviam de "fonte primária para outros veículos" e não precisavam oferecer sempre informação concluída. As redações, por outro lado, privilegiariam a contextualização da informação, uma vez que seu material volta-se a um público mais amplo.

${ }^{3}$ Neste cenário, parece-nos estar em xeque a própria noção de "fato jornalístico", que, tradicionalmente, determina elevação de um acontecimento ao status de notícia. Caracterizado por Genro Filho (1987) como "um recorte no fluxo contínuo", o fato jornalístico, inclusive na internet, pode ser substituído pela atualização ininterrupta de informações de relevância não muito clara, principalmente se considerarmos os parâmetros clássicos de valores-notícia estabelecidos pela imprensa.
} 
difícil a identificação do que é o "fato jornalístico", ou onde começa e termina a sequência de fatos que deve ser reportada ${ }^{3}$.

Esta dinâmica é chamada por Barbosa (2008) de "densidade informativa", que é uma das categorias do Jornalismo Digital em Base de Dados (JDBD) proposto pela autora. Usada para "explicar sucessão de notícias na informação on-line disponibilizada de maneira contínua", a densidade informativa prevê o desdobramento de um conteúdo jornalístico, que pode partir de uma "baixa resolução", quando há poucos dados confirmados sobre um acontecimento, até uma situação de alta resolução, em que a apuração e edição são ampliadas para um material mais definitivo. Esta mudança acontece "à medida que mais informações forem sendo apuradas, inclusive, pesquisando-se em BDs, ela vai sendo complementada, alterada, corrigida, contextualizada, aprofundada tanto pelos profissionais de um produto como pela participação dos usuários" (p.234-235).

Para Barbosa (2008), a incorporação de uma "oferta informativa mais abrangente e diversificada" na rotina de produção jornalística está diretamente ligada à adoção de bases de dados e softwares gerenciadores pelas redações. No mesmo sentido, Langeveld (2009) destaca o papel que os wikis podem assumir na organização dos fluxos de informação jornalística, em função da possibilidade de edição contínua de informações e, em algum grau, da abertura à participação de um público mais amplo, conforme discutiremos a seguir.

\section{Participação do público}

A participação direta do público leigo é uma variável crescente na atual dinâmica de produção e circulação de informações, inclusive de caráter jornalístico, na internet. $\mathrm{O}$ uso disseminado de ferramentas on-line de publicação de informações, especialmente aquelas estruturadas em torno de redes sociais, permite que não-especialistas, articulados entre si, tornem-se tão (ou mais) relevantes que publicações e profissionais institucionalizados na atividade jornalística.

Nesse cenário, é cada vez mais comum, por parte das empresas jornalísticas, a abertura, menos ou mais intensa, à colaboração do público leigo, numa prática conhecida como "jornalismo colaborativo", aqui entendido como a co-participação do público em uma ou mais etapas da rede de produção jornalística, como a elaboração de pautas, apuração, redação, edição e/ou hierarquização das matérias. Especificamente na etapa de edição do conteúdo jornalístico, a participação do público pode variar de uma abertura total por parte das instituições jornalísticas à limitação da abertura a uma etapa ou a uma função do processo. Para problematizar estas possibilidades, adotamos a classificação proposta por Machado (2008), que, baseado em Bruns (2005), relaciona três modelos de edição no ciberjornalismo.

O primeiro modelo delineado pelo autor está baseado em sistemas de edição compartilhada em ciberjornalismo. Para Machado (2008), nestes sistemas não há uma ruptura do modelo tradicionalmente estabelecido pelas redações jornalísticas, uma vez que a participação do público está limitada às etapas iniciais da produção. Ainda que o público possa sugerir pautas ou enviar ma- 
terial, a estrutura verticalizada mantém as escolhas finais sob o controle dos profissionais. Um exemplo deste modelo é o jornal sul-coreano Ohmynews.

O modelo baseado em sistemas de revisão aberta em ciberjornalismo é caracterizado por uma participação dos membros da rede de colaboradores - inclusive o público - em um maior número de etapas da produção jornalística. Segundo Machado (2008), "este tipo de sistema pressupõe uma horizontalização que vá além da pré-edição existente nos conteúdos submetidos pelos colaboradores na edição compartilhada", o que caracterizaria uma maior complexidade nos processos de edição, uma vez que "aumenta o número de mediações" e criam-se "múltiplas funções para todos os envolvidos" (p.8). Um exemplo deste modelo é o site Kuro5hin. Neste modelo podemos enquadar também os "wikis de segunda versão", em que colaboradores e jornalistas revezam-se na edição de um texto pautado previamente, porém, a versão final é de responsabilidade do profissional de redação (D'ANDRÉA, 2009b, p. 83).

O terceiro modelo descrito está baseado em sistemas de edição aberta em ciberjornalismo, caracterizado por uma "horizontalização total" do processo de edição, com todos os membros da rede podendo alterar todos os conteúdos. Essa abertura sem restrições, afirma Machado (2008), culmina numa "ruptura completa com o sistema de edição existente no jornalismo convencional", uma vez que ignora as "competências e conhecimentos específicos de cada um" dos colaboradores (p.9). O "exemplo paradigmático" citado pelo autor é o Wikinews. Trata-se do modelo que denominamos anteriormente de "wikis abertos" (D’ANDRÉA, 2009b).

A gradual abertura à participação de colaboradores, conforme categorização acima, significa, para o jornalista, assumir progressivamente o papel de gatewatcher (BRUNS, 2005), função que se caracteriza por uma filtragem seletiva da grande quantidade de informações geradas e publicadas na web, inclusive por usuários comuns. Este modelo opõem-se à figura clássica do gatekeeper, um mediador responsável pela filtragem do que seria ou não relevante para ser publicado como notícia em uma publicação.

\section{Por uma wikificação do jornalismo}

Does editing disappear along with the editor? (GREENBERG: 2010, p.7)

A instigante pergunta que dá nome ao artigo mais recente da pesquisadora britânica é um bom ponto de partida para problematizarmos o "futuro" da edição (aqui entendida, como dissemos, como a adequação de um conteúdo jornalístico a um determinado conceito editorial). Em um contexto de fragilização e, em alguns casos, supressão do profissional responsável por essa atividade, o esvaziamento da edição jornalística tradicional coincide com uma emergente necessidade de complexificação dos processos, principalmente devido à gradativa abertura à colaboração de sujeitos externos à equipe de profissionais.

Nesse contexto, parece-nos fundamental a discussão de rotinas de produção e de formatos de publicação de conteúdo que deem conta do fluxo contínuo, fragmentado e heterogêneo de informações que permeiam as redações voltadas para publicação na web. Em d'Andréa (2009b), apresentamos a noção de "wikificação do jornalismo" para designar uma prática emergente de edição 
de textos. O conceito é baseado no fenômeno que Kosik (2008) chamou de "wikificação do conhecimento". O autor (um neurocientista) destaca a crescente importância - assim como os riscos e os benefícios - de atividades baseadas na autoridade (como a medicina e o jornalismo, conforme exemplos de Kosik) compartilharem com leigos a gestão de informações de sua atividade profissional.

A palavra "wikificação", evidentemente, remete-nos à ferramenta wiki, caracterizada pela abertura à participação de qualquer interessado na formulação de um texto e pelo entendimento de que um texto é sempre passível de melhorias e de atualizações, o que torna inviável e desnecessária a edição de uma versão final e acabada. Outra característica marcante dos wikis é o acesso irrestrito ao histórico de edições de uma página, o que permite não só a identificação do autor e do conteúdo modificado, mas ainda a reversão imediata de uma atualização considerada inadequada.

A aplicação mais bem sucedida da plataforma é a Wikipédia, uma enciclopédia colaborativa fundada em 2001 e que, em abril de 2010, possui versão em cerca de 270 línguas e dialetos. Em construção por editores voluntários, o site é um dos cinco mais populares do mundo na atualidade e baseia sua rotina de produção na meritocracia - quanto mais contribui, mais prerrogativas técnicas um editor pode conquistar. A tentativa de equilíbrio entre qualidade e quantidade de edições pode ser entendida a partir da produtiva tensão entre abertura à participação de qualquer usuário - inclusive não-cadastrados - e o enrijecimento dos mecanismos e das políticas de controle, principalmente pelos administradores do site (cf. D`ANDRÉA, 2009c).

Por ser uma enciclopédia, a Wikipedia não permite a publicação de informações primárias, ou inéditas, o que a diferencia radicalmente de produtos editoriais de caráter jornalísti-

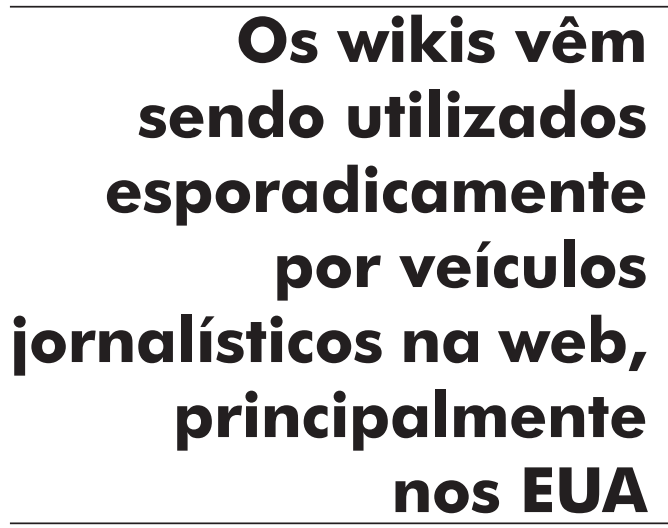
co, que tem a "novidade" como pré-requisito para seu gênero principal (a notícia). No entanto, ao permitir que a edição dos verbetes (ou artigos) aconteça no ritmo de acontecimentos factuais, a Wikipédia assume um caráter jornalístico que a aproxima de práticas editorais comuns em jornais e sites noticiosos (COHEN, 2008). Trata-se de "agregação em tempo real", como afirmou Mola Pantages, coordenadora de comunicação da Fundação Wikimedia, ao ressaltar a curadoria de diferentes fontes de informação feita por pessoas (e não algoritmos) como um dos grande méritos da Wikipédia (cf. MELANSON, 2010).

Os wikis vêm sendo utilizados de forma esporádica por veículos jornalísticos na web, principalmente nos Estados Unidos. Bradshaw (2007) chama de "wiki-jornalismo" as diferentes práticas e possibilidades de uso desta ferramenta, conforme taxonomia proposta em seu artigo (p.05). Os cinco modelos de "wiki jornalismo" mapeados pelo autor incluem a produção distribuída de conteúdos cuja execução seria inviável pela equipe editorial (Crowdsourcing wiki), um ambiente complementar a algum relato jornalístico previamente publicado (Supplementary wiki) e um wiki restrito aos colaboradores internos, incentivando a autoria coletiva (Logistical wiki), além dos wikis abertos e de "segunda versão" (Second draft) citados anteriormente. 
Para Tapscott e Willians (2006, p. 18), “wiki é mais que um programa que permite que múltiplas pessoas editem sites. É uma metáfora para uma nova era de colaboração e participação" que os autores chamam de "wikonomics". Neste sentido, mais do que uma prática associada a uma ferramenta, caracterizamos a "wikificação do jornalismo" como um modelo de edição que procura associar as rotinas de produção do texto jornalístico à abertura, em maior ou menor grau, para participação de membros externos à equipe, assim como sua adequação à atual lógica de fluxo contínuo de informações, privilegiando a edição constante de textos jornalísticos, em detrimento da publicação pulverizada e sequenciada de páginas avulsas com "fatos” novos.

Uma wikificação dos processos jornalísticos, especialmente no que tange à reelaboração constante de textos publicados em um site, dialoga com um conceito mais amplo, comum principalmente na adminstração de sites no contexto institucional: a gestão de conteúdo. Lapa (2004) define gestão de conteúdo como:

um conjunto de técnicas, modelos, definições e procedimentos de ordem estratégica e tecnológica, visando integração e automatização de todos os processos relacionados à criação, agregação, personalização, entrega e arquivamento de conteúdos de uma organização (p.40).

A definição e adoção de um modelo de gestão de conteúdo, portanto, significa um esforço de racionalização, integração e centralização tecnológica dos processos de produção de conteúdo em um dado contexto. No jornalismo, a adoção dessa perspectiva está associada à adotação, pelas redações jornalísticas, de softwares gerenciadores de conteúdo (CMSs, em inglês). Conforme Correia e Schwingel (2008), a utilização de aplicativos associados a banco de dados despertou nas empresas de comunicação "a necessidade de utilizar sistemas de gerenciamento de conteúdos mais complexos e adaptados minimamente à produção da notícia, às dinâmicas jornalísticas” (p.13). Para Machado (2008, p.5), uma plataforma tecnológica completa para o jornalismo "pressupõe a integração entre os subsistemas de apuração, produção e circulação".

O grande desafio, como afirmam Correia e Schwingel (2008), é a adequação das ferramentas e inovações aos fluxos de trabalho e aos processos organizacionais. Neste cenário, um ponto crítico é a incorporação de membros externos com diferentes níveis de comprometimento e conhecimento técnico num fluxo de produção que pretende ser tão organizado e racional quanto a atividade jornalística, marcada essencialmente pela imprevisibilidade e pela novidade, pode ser. Para Machado (2008), um caminho seria aumentar os processos de edição, isto é, "radicalizar a mediação jornalística, complexificando o número de etapas do processo de edição ao mesmo tempo em que se incorpora todos os membros de cada rede no máximo possível destas etapas” (p.12). Para o autor, esta complexificação valoriza ao invés de esvaziar o trabalho dos profissionais.

Embora concordemos com a importância da presença atuante do jornalista nas etapas de edição, é fundamental registramos a existência de novos modelos de gestão de conteúdo que, por atuar de forma distribuída, prescindem 
parcial ou até totalmente da mediação de profissionais. No caso da Wikipédia, por exemplo, a combinação entre a participação eventual de muitos colaboradores e o grande engajamento de um grupo restrito de editores parece criar condições para a formação de uma dinâmica editorial "auto-organizada"4 e eficiente, embora não isenta de conflitos.

\section{Considerações finais}

O contexto apresentado nas discussões iniciais do artigo - em síntese, a fragmentação do texto jornalístico em função do fluxo contínuo de informações e a crescente participação de membros externos na elaboração de notícias - culmina, ao nosso ver, na necessidade de uma nova sistematização dos processos de produção nas redações, principalmente naquelas voltadas para publicação na web.

A "wikificação do jornalismo", um modelo de gestão de conteúdo baseado na colaboração e na atualização contínua de textos, parece-nos capaz de dar conta ao novo grau de complexidade esperado da edição jornalística, principalmente frente ao esvaziamento das rotinas tradicionais. Nesse sentido, parece-nos viável que uma estrutura verticalizada e rígida da produção seja substituída por um fluxo mais horizontalizado, em que a ausência e flexibilização de uma hierarquia estabelecida a priori possa ser compensada por um aumento no número de mediações e pela diversidade de funções cumpridas pelos envolvidos.

Trata-se, evidentemente, de um dos modelos possíveis para lidar com a quantidade e diversidade de dados a serem considerados na atual conjuntura informacional. Greenberg (2010, p.10), ao elencar os diferentes exemplos de edição existentes na internet, ressalta a necessidade de "ter consciência de todos os níveis e tipos de processos, do mais automático ao mais manual, do mais profissional ao mais amador". Dentre os modelos de edição propostos por Machado (2008), por exemplo, acreditamos que a wikificação no jornalismo pode funcionar não só como um sistema de edição aberta em ciberjornalismo, mas também como um sistema de revisão aberta, uma vez que a própria plataforma wiki possui mecanismos técnicos de moderação prévia das atualizações. Esta definição dependerá do assunto a ser tratado e da visibilidade dada ao conteúdo wikificado - quanto mais polêmico e factual o assunto e maior o destaque dado à experiência, maior a chance de ocorrência de vandalismos e abusos. Esses desvios foram identificados, por exemplo, no registro do Surto de Gripe Suína na Wikipédia em português (D`ANDRÉA e ESTEVES, 2009) e em iniciativas jornalísticas como o wikitorial sobre a Guerra do Iraque no site do LATimes (BRADSHAW, 2007), entre outras situações.

\footnotetext{
${ }^{4}$ Baseado no paradigma da complexidade, entendemos "auto-organização" como a condução da evolução de um sistema pelas interações entre os agentes distintos e independentes (em parte, pelo menos) que o compõem. Conforme Debrun (1996, p.4), "há auto-organização cada vez que o advento ou a reestruturação de uma forma, ao longo de um processo, se deve principalmente ao próprio processo (...)". Em d'Andréa (2009a) propomos uma relação entre os processos editoriais na Wikipédia e o conceito de auto-organização.
} 


\section{Referências bibliográficas}

BARBOSA, Suzana. Jornalismo Digital em Ambientes Dinâmicos. Propriedades, rupturas e potencialidades do Modelo JDBD. In: Observatorio (OBS*) Journal, V. 2, N. 1, 2008, p.217-244.

. Sistemas de produção de conteúdos em portais regionais: os casos UAI e iBAHIA. In: I Encontro Nacional da Sociedade Brasileira dos Pesquisadores em Jornalismo (SBPJor), 2003, Brasília. Anais... Brasília: Casa das Musas, 2003. p. 04-47.

BETTI, J.G.; MEDITSCH, Eduardo. O formato all-news no rádio brasileiro: importação, estranhamento ve adaptação. In: VI SBPJOR, 2008, São Bernardo do Campo. VI SBPJor. São Bernardo dos Campos : SBPJor-Umesp, 2008.

BRADSHAW, Paul. Wiki Journalism Are wikis the new blogs? In: Future of Newspaper Conference. Cardiff, Setembro 2007. Disponível em <http:// onlinejournalismblog.files. wordpress.com/2007/09/wiki_journalism.pdf $>$. Acesso em: 10 abr. 2008

BRUNS, Axel. Gatewatching: collaborative online news production. New York: P. Lang, 2005.

COHEN, Noan. Updating a Reference Site on the Fly. New York Times. Publicado em 09 nov. 2008. Disponível em <www.nytimes.com/2008/11/10/ technology/internet/10link.htm >. Acesso em 13 abr. 2009.

CORREIA, Ben-Hur, SCHWINGEL, Carla. Sistemas aplicados ao Ciberjornalismo: gestão de conteúdos e produção jornalística. VI Encontro $\mathrm{Na}$ cional de Pesquisadores em Jornalismo (6 SBPJor), 2008, São Bernardo (SP). Anais..., 2010

D'ANDRÉA, Carlos. Auto-organização e processos editoriais na Wikipédia: uma análise à luz de Michel Debrun. III Encontro Nacional sobre Hipertexto, 2009, Belo Horizonte. Anais..., 2009a.

. Colaboração, edição, transparência: desafios e possibilidades de uma "wikificação" do jornalismo. In: SOSTER, D. E FIRMINO, F. Metamorfoses jornalísticas 2 - a reconfiguração da forma. Santa Cruz do Sul: Edunisc, 2009b. p.73-89.

. Em Busca Do "Artigo Perfeito": O Ciclo de Vida dos Textos na Wikipédia. Texto Livre, Belo Horizonte, v.1 , n.2, p. 1-9, 2009 c.

D'ANDRÉA, Carlos. F. B.; ESTEVES, B. Disputas, vandalismos, reversões: a dinâmica de edições dos artigos sobre a gripe suína na Wikipédia em português. In: III Simpósio Nacional ABCiber, 2009, São Paulo. Anais.... São Paulo, 2009.

DUARTE, Alec. Passaralhos vitimam mais editores e redatores, não repórteres. Webmanário. Publicado em 19 ago. 2010. Disponível em <http://webmanario. wordpress.com/2009/ 08/19/ passaralhos-vitimam-mais-editores-eredatores-nao-reporteres/ $>$. Acesso em 20 mar. 2010.

DEBRUN, Michel. A Idéia de Auto-Organização. In: DEBRUN, $\mathrm{M}$ et al. Auto-Organização Estudos Interdisciplinares. Coleção CLE 18, Campinas, 1996, p. 3-23.

GENRO FILHO, Adelmo. O Segredo da Pirâmide: para uma teoria marxista do jornalismo. 2.ed. Porto Alegre: Ortiz, 1987.

GREENBERG, Susan. When the Editor Disappears, Does Editing Disappe- 
ar? Convergence: The International Journal of Research into New Media Technologies. Vol. 16, n.1., p.7-21, 2010.

JORGE, T. M. A notícia em mutação. Estudo sobre o relato noticioso no jornalismo digital. Tese (Doutorado em Comunicação) - Universidade de Brasília, Programa de Pós-Graduação em Comunicação, Brasília, 2007.

KOSIK, Kenneth S. The Wikification of Knowledge. Nieman Report. Winter 2008. Disponível em <http://www.nieman.harvard.edu/reportsitem. aspx? $\mathrm{id}=100690>$. Acesso em 05 fev. 2009.

LANGEVELD, Martin. The content cascade: How content will flow in digital news enterprises. Nieman Journalism Lab. Publicado em: 07 abr. 2009. Disponível em < http://www.niemanlab.org/2009/04/managing-the-content-cascade/> Acesso em 15 abr. 2009.

LAPA, Eduardo. Gestão de Conteúdo: rumo à gestão de conhecimento. Rio de Janeiro: Brasport, 2004; Coleção Webinsider.

MACHADO, Elias. Sistemas de edição no jornalismo em bases de dados. Palestra de abertura da XVII Semana de Comunicação da UEPG, 2008. Disponível em <http://posjor.ufsc.br/public/docs/203.pdf> Acesso em 20 mar. 2010.

MAROCCO, Beatriz e BERGER, Christa. A dupla falta do editor de jornal, no livro e cursos de jornalismo. In: FELIPPI, A.; SOSTER, D. A.; PACCINI, F. Edição em Jornalismo - Ensino, Teoria e Prática. RS: Edunisc, 2006. p.1730

MARTINEZ, Adriana Garcia. A construção da notícia em tempo real. In: FERRARI, Pollyana (Org.). Hipertexto Hipermídia. São Paulo: Contexto, 2007. p.13-27.

MELANSON, Mike. Why Wikipedia Should Be Trusted As A Breaking News Source. Read Write Web. Publicado em 15 mar. 2010 Disponível em < http:// www.readwriteweb.com/ archives/ why_wikipedia_should_be_trusted_or_ how_to_consume.php >. Acesso em 15. mar. 2010.

PEREIRA, Fábio H. O 'Jornalista Sentado' e a produção da notícia on-line no Correioweb. Em Questão (UFRGS). Porto Alegre (RS), v. 10, n. 01, p. 95-108, 2004.

PEREIRA JÚNIOR, Luiz Costa. Guia para a edição jornalística. Rio de Janeiro: Vozes, 2006.

SILVA JUNIOR, J. A. Legado e Herança das agências de notícias para o jornalismo na web. Contemporânea - Revista de Comunicação e Cultura POSCOM/UFBA, v. 6, p. 8, 2008.

SOSTER, Demétrio de A. Ensino de edição em jornais impressos: uma abordagem metodológica. In: FELIPPI, A.; SOSTER, D. A.; PACCININ, F. Edição em Jornalismo - Ensino, Teoria e Prática. Santa Cruz do Sul: Edunisc, 2006. p.31-45

STEPP, Carl Sessions. The Quality-Control Quandary. American Journalism Review. Mar./Abr. 2009. Disponível em <http://www.ajr.org/article. asp?id=4742>. Acesso em 11 abr. 2009.

TAPSCOTT, Don; WILLIANS, Anthony D. Wikiconomics: how mass collaboration changes everything. Nova York: Portifolio, 2006. 